\title{
Understanding per-capita income growth in preindustrial Europe
}

\author{
Nils-Petter Lagerlöf \\ Email: lagerlof@econ.yorku.ca
}

\begin{abstract}
Fouquet and Broadberry (Journal of Economic Perspectives 2015) have recently compiled detailed time-series data over per-capita incomes for several European countries from as early as 1300 up to 1800. The time series are all volatile and highly persistent; per-capita incomes move in decades-long cycles of expansions and contractions. The current paper examines a Malthusian model with realistic life-cycle structure, and stochastic and increasing rates of growth in agricultural productivity. This model can generate per-capita income dynamics that are qualitatively and quantitatively similar to the Fouquet-Broadberry data.
\end{abstract}




\section{Introduction}

A common understanding of Malthusian models is that they predict per-capita incomes to be independent of land productivity. In a Malthusian world, if one economy has higher agricultural productivity than another, they should still have the same standards of living, as long as they are otherwise identical. Changes over time in land productivity should not translate into changes in living standards.

This contrasts with what we see in the data for several supposedly Malthusian societies. Fouquet and Broadberry (2015) have used various sources to compile annual per-capita GDP data for a handful of European countries from as early as 1300, up to 1800. These all display big fluctuations in per-capita GDP over time, and on average the levels seem to trend upwards (see Figure 1).

However, those predictions refer to steady state outcomes in a non-stochastic environment with land productivity being constant or growing at a constant rate. If Malthusian economies are constantly hit by random shocks to land productivity, then per-capita incomes always differ from the steady-state level associated with the corresponding non-stochastic version of the model. In fact, as this paper tries to demonstrate, in a stochastic Malthusian environment, per-capita incomes can differ a great deal between any two economies, and they can be highly persistent over time within economies, on an order of magnitude comparable to the Fouquet and Broadberry data. Moreover, if growth rates in land productivity trend upward over time, then average per-capita incomes will too.

To make this point, I examine an otherwise standard Malthusian model with some crucial extensions. First, the model has a realistic life-cycle structure, with each period representing one year. This allows for comparison to annual data, like those compiled by Fouquet and Broadberry (2015). Second, it allows for growth in land productivity, and the growth rate is both stochastic and increasing over time. That the growth rate is stochastic means percapita incomes will fluctuate and exhibit persistence; that the mean growth rate is increasing over time implies that per-capita incomes are too, by amounts proportional to the changes in the growth rates.

The model otherwise relies on standard Malthusian building blocks. Fertility enters the utility function as a normal good, making higher per-capita incomes induce faster population growth, and land is in fixed supply, making per-capita incomes decline when population levels expand. The model is thus by construction unable to generate sustained growth in per-capita incomes.

To explore the predictions of the model I set parameters at what seems like plausible values. Then I run a Monte Carlo simulation across 1000 model economies. For each simulated economy I can measure the standard deviation and serial correlation in per-capita incomes over 500 years, and then compare these to data. 
Qualitatively, the model-generated paths are strikingly similar to those in the data, with several expansions and contractions lasting many decades, and in some cases more than a century. Quantitatively, it is not difficult to generate levels of persistence (serial correlation at one- and two-year lags) and standard deviations similar to what we see in the data.

This paper seeks to add to a broad literature on long-run economic development. This is an important topic, because it is often argued that the origin of today's world income distribution can be traced in one way or another to the timing of the transition of a few economies in Western Europe out of what is typically labeled Malthusian stagnation (e.g., Galor and Weil 2000, Hansen and Prescott 2002, Lucas 2002, Galor 2008).

Some authors put forward a non-stagnant preindustrial environment of many economies as an argument for rejecting the validity of the standard Malthusian model. For example, Wu et al. (2014) argue that an extended Malthusian setting allowing for other goods than food can better account for the empirical facts; see also Sharp et al. (2012). Here I do not seek to diminish the importance of these contributions; the analysis of two-good Malthusian models can be motivated independently of the lack of stagnation in the data discussed here. However, my exercise can shed light on whether such extensions are needed to account for the observed volatility and persistence of per-capita income paths in Europe prior to 1800.

Several papers have calibrated growth models to similar data, often with an aim to produce a transition from stagnation to growth in per-capita incomes (e.g., Fernández-Villaverde 2001; Lagerlöf 2003, 2006; Bar and Leukhina 2010). This paper is probably the first to examine whether a purely Malthusian model, with realistic life cycles and shocks to land productivity, may appear to generate transition-like time paths.

Finally, this paper is motivated by other evidence that the preindustrial world was Malthusian. Across regions defined by modern country borders, preindustrial levels of technology correlate more strongly and robustly with population densities than with living standards (Ashraf and Galor 2011). Moreover, the very same preindustrial economies displaying non-stagnant incomes in the Fouquet-Broadberry data seem to react in a Malthusian fashion to exogenous changes in per-capita incomes. Across Swedish counties in the 19th century, a good harvest one year was associated with higher birth rates, lower death rates, and higher marriage rates in the following year (Lagerlöf 2015). Similar patterns have been found for England, both in aggregate time-series data (Nicolini 2007, Crafts and Mills 2009), and at the parish level (Kelly and Ó Gráda 2010).

The rest of this paper is organized as follows. Section 2 summarizes some of the facts about per-capita incomes in preindustrial Europe, as uncovered by Fouquet and Broadberry (2015) and their sources. Section 3 sets up the model. Section 4 presents the results from a Monte Carlo simulation and compares these to the data. Finally, Section 5 ends with concluding discussion. 


\section{The facts}

Figure 1 shows log per-capita GDP for five economies (with periods indicated in parenthesis): England/UK (1300-1800), Italy (1310-1800), the Netherlands (1348-1800), Portugal (15301800), and Sweden (1560-1800). The data in Figure 1 are reported in logs and normalized so that the means over time equal one (or zero in logs) for each country. This filters out time-invariant cross-country income gaps and facilitates comparison to our simulation results later.

The source for this data is Fouquet and Broadberry (2015), who in turn rely on various in-depth studies for the respective countries. ${ }^{1}$ They also report data from Spain but not on annual frequency so we do not use those numbers here.

Four things can be noted from Figure 1. First, average log GDP per capita across the five countries shows a mild upward trend over time.

Second, per-capita GDP was not constant over this period, but fluctuated a lot for all countries. Any model that seeks to replicate such time series needs to have a stochastic element to it.

Third, the time series show a great deal of persistence. A country's level of per-capita GDP in any given year is highly correlated with where it was in the previous year, and even two or three years back. Put another way, GDP per capita expands and contracts over long periods, rather than jumping all over the place form one year to another.

Fourth, while the time paths do show some correlation between countries, they are far from synchronized. Some countries are relatively poor in periods when others are relatively rich, and vice versa.

\section{The model}

\subsection{Agents and fertility decisions}

Consider the following overlapping-generations model. Agents live for $T$ periods, but are economically and reproductively active only from periods $\underline{B}$ to $\bar{B}$, where $1<\underline{B}<\bar{B}<T$.

In each period $t$, active agents of age $j \in\{\underline{B}, \ldots, \bar{B}\}$ earn a wage $w_{j, t}$. This is allocated between own consumption in the same period, $c_{j, t}$, total transfers to non-active offspring, $\tau_{j, t}$, and spending on conceiving $n_{j, t}$ children, at cost $q$ per child. This gives the budget constraint

$$
c_{j, t}=w_{j, t}-\tau_{j, t}-q n_{j, t} .
$$

\footnotetext{
${ }^{1}$ The original sources are as follows: England/UK: Broadberry et al. (2011); Italy: Malanima (2011); Netherlands: van Zanden and van Leuwen (2012); Sweden: Schön and Krantz (2012); Portugal: Reis et al. (2013) and Palma and Reis (2014).
} 
Utility is defined over the active phase of life. An agent who becomes active in period $t$ has utility

$$
U_{t}=\sum_{j=\underline{B}}^{\bar{B}} \beta^{j-\underline{B}} u_{j, t+(j-\underline{B})},
$$

where $u_{j, t}$ is the direct utility at age $j$ in period $t$, and $\beta$ is a discount factor. Active agents care about their own consumption, transfers to non-active offspring (and possibly non-active parents), and the number of children conceived. The period-utility can thus be written

$$
u_{j, t}=(1-\delta-\widetilde{\gamma}) \ln \left(c_{j, t}\right)+\delta \ln \left(\tau_{j, t}\right)+\widetilde{\gamma} \ln \left(n_{j, t}\right) .
$$

Because agents have no means of allocating resources intertemporally, they simply maximize the direct utility in every period, as given by (3), subject to the budget constraint in (1). This gives fertility as

$$
n_{j, t}=\gamma w_{j, t}
$$

where

$$
\gamma=\frac{\widetilde{\gamma}}{q}
$$

is the effective rate at which resources earned by active agents are transformed into a new generation of agents. This is the first Malthusian building block of the model: higher wages lead to more reproduction.

For internal consistency of the model, we may also specify consumption of non-active agents. Dependent children, of ages $j \in\{1, \ldots, \underline{B}-1\}$, simply rely on transfers from their parents, but because they do not work or reproduce, these transfers play no role in the rest of the analysis. To model consumption of old agents, of ages $j \in\{\bar{B}+1, \ldots, T\}$, we can make several assumptions. For example, they can be partial recipients of the transfers their active children make (sharing with their grandchildren), or they can be owners of land and earn rental income from that, as discussed below. The latter interpretation means that agents receive an amount of land when they pass from age $\bar{B}$ to $\bar{B}+1$, as inheritance from agents of age $T$ in the previous period. Like children, old agents are also non-active and their incomes or consumption play no role in the rest of the analysis.

\subsection{Production and land productivity}

In any period $t$, total output of a single good, $Y_{t}$, is determined by a Cobb-Douglas production function, with land and effective labor as inputs:

$$
Y_{t}=\left(X_{t} A_{t}\right)^{\alpha} L_{t}^{1-\alpha},
$$

where $L_{t}$ is effective labor (explained further below), $\alpha$ is the land share of output, and the amount of land is normalized to unity. Land productivity in period $t$ equals $X_{t} A_{t}$, where 
$X_{t}$ and $A_{t}$ are subject to temporary and permanent shocks, respectively. These shocks are distributed as follows:

$$
\ln \left(X_{t}\right) \sim N\left(0, \sigma_{X}\right)
$$

and

$$
\ln \left(A_{t+1}\right)-\ln \left(A_{t}\right) \sim N\left(\mu_{t}, \sigma_{A}\right),
$$

where $\mu_{t}$ is assumed to be time-dependent, thus allowing growth in land productivity to change deterministically over time, and $\sigma_{X}$ and $\sigma_{A}$ measure dispersion in the temporary and permanent shocks, respectively. Temporary shocks could represent fluctuations in weather, and permanent shocks could capture variation in the rate of improvement in agricultural technology.

Effective labor is determined by a CES aggregation function, allowing flexible substitutability between labor inputs at different ages:

$$
L_{t}=\left[\sum_{j=\underline{B}}^{\bar{B}} \beta_{j} P_{j, t}^{\rho}\right]^{\frac{1}{\rho}},
$$

where $\rho<1$, and $\sum_{j=\underline{B}}^{\bar{B}} \beta_{j}=1$. The most standard assumption might be that $\rho=1$, and $\beta_{j}$ is constant across age cohorts, implying perfect substitutability between labor supply of different cohorts. The alternative assumption ( $\rho<1$, and $\beta_{j}$ being different across cohorts) can be interpreted as different age cohorts performing different work tasks, perhaps because older workers have more experience, and younger workers more physical strength. This allows the age distribution in any given period to have an effect on output, and thus incomes, and reproduction.

\subsection{Wages}

Recall that the wage of an agent of age $j$ in period $t$ is $w_{j, t}$, which equals the marginal product of age- $j$ labor in period $t$. Some algebra shows that

$$
w_{j, t}=\frac{\partial Y_{t}}{\partial L_{t}} \frac{\partial L_{t}}{\partial P_{j, t}}=(1-\alpha) \frac{Y_{t}}{L_{t}} \beta_{j}\left(\frac{L_{t}}{P_{j, t}}\right)^{1-\rho} .
$$

Using (9) and (10) it can be seen that total payments to workers equals

$$
\sum_{j=\underline{B}}^{\bar{B}} w_{j, t} P_{j, t}=(1-\alpha) Y_{t}
$$

The remaining output, $\alpha Y_{t}$, is allocated to landowners. These could either be old and nonactive agents of ages $j \in\{\bar{B}+1, \ldots, T\}$, who use their income for consumption. Alternatively, land income could be allocated to a class of elite agents of small and fixed size, rearing only one offspring per agent, and using the reminder of their income for consumption. 


\subsection{Population dynamics}

The new-born population in period $t+1, P_{1, t+1}$, is made up of children conceived in period $t$. Each reproductive agent, of ages $j \in\{\underline{B}, \ldots, \bar{B}\}$, conceives $n_{j, t}$ children, and since there are $P_{j, t}$ in each such cohort, it follows that

$$
P_{1, t+1}=\sum_{j=\underline{B}}^{\bar{B}} n_{j, t} P_{j, t}
$$

From (4), (10), and (12) it can be seen that

$$
P_{1, t+1}=\sum_{j=\underline{B}}^{\bar{B}} n_{j, t} P_{j, t}=\sum_{j=\underline{B}}^{\bar{B}} \underbrace{(1-\alpha) \frac{Y_{t}}{L_{t}} \beta_{j}\left(\frac{L_{t}}{P_{j, t}}\right)^{1-\rho}}_{w_{j, t}} P_{j, t},
$$

which, upon applying (9), simplifies to

$$
P_{1, t+1}=\gamma(1-\alpha) Y_{t} .
$$

That is, the size of the new-born population in any given period depends only on total output in the preceding period. This particular closed-form solution hinges on the linear relationship between fertility and wages in (4), but other formulations can be seen to generate qualitatively similar results.

For all other cohorts, population levels evolves according to

$$
P_{j+1, t+1}=\left(1-d_{j}\right) P_{j, t},
$$

where $d_{j} \in[0,1]$ denotes the rates at which agents die at ages $j \in\{1, \ldots, T\}$, which we here assume to be time-independent. Since agents die after living $T$ periods, we have $d_{T}=1$.

\subsection{Total population and per-capita incomes}

Let total population be denoted just

$$
P_{t}=\sum_{j=1}^{T} P_{j, t}
$$

In any given period $t$, and for any given levels of output, $Y_{t}$, and total population, $P_{t}$, the economy-wide per-capita income level becomes

$$
y_{t}=\frac{Y_{t}}{P_{t}} .
$$

In what follows, we shall let $y_{t}$ in the model correspond to GDP per capita in the data. 


\section{Quantitative analysis}

\subsection{Parameter values}

The next task is to simulate time paths for the different variables, in particular $y_{t}$, and compare to data. Most of the parameter values are explained in Table 1.

The life-cycle parameters, $T, \underline{B}$, and $\bar{B}$, can be set very intuitively. Agents here live for $T=90$ years and work and reproduce between ages $\underline{B}=18$ and $\bar{B}=40$. The age-specific death rates are set as in Table 2 , which uses average death rates for different age groups in Sweden 1750-1800 (Statistics Sweden 1969, Table 40).

The parameters $\beta_{j}$, where $j \in\{\underline{B}, \ldots, \bar{B}\}$, measure the importance of each cohort in the labor aggregation in (9). These are set such that $\beta_{j}$ is $50 \%$ larger for older cohorts than younger from $j=\underline{B}=18$ to $j=32$, and then $50 \%$ lower for older cohorts from age $j=32$ to age $j=\bar{B}=40$, with $\sum_{j=\underline{B}}^{\bar{B}} \beta_{j}=1$. Table 3 gives the implied values for three cohorts.

The land share of output, $\alpha$, is set as in the parametrization for the Malthus sector in Hansen and Prescott (2002).

The time path for the growth rate in land productivity, $\mu_{t}$, is set such that the growth rate increases from $0 \%$ per year in 1300 to $1 \%$ in 1800, with more of the increase coming toward the end of that period. This makes the model match the rise seen in Figure 1 in mean levels of log GDP per capita across the five countries. Intuitively, in a (non-stochastic) Malthusian model with sustained growth in land productivity, per-capita income levels on a balanced growth path are proportional to the productivity growth rate, so letting growth rates increase slowly over time generates a slow rise in per-capita income levels.

The parameters measuring the dispersion in the shocks in (7) and (8), $\sigma_{X}$ and $\sigma_{A}$, are set so that the Monte Carlo simulations generate measures of standard deviation in ln $y_{t}$ over time, and serial correlations at different time lags, similar to the corresponding numbers in the data, as explained in connection to the results in Figure 4 below.

Some of the remaining parameters, e.g. $\gamma$ and $\rho$, are set a bit arbitrarily, although the results are broadly robust to alternative values.

\subsection{Simulation results}

The explore the model, I ran a Monte Carlo simulation, letting 1000 model economies be hit by different shocks over 500 periods (each period being one year). These shocks were drawn from the same distribution and parameter values were set as described above.

Figure 2 shows examples of what the time paths for $\ln y_{t}$ may look like, as defined by (17) and corresponding to GDP per capita in the data. The figure also shows the mean of $\ln y_{t}$ in each year across all 1000 runs, which can be seen to show a mild upward trend. Recall 
that this is driven by the upward drift in land productivity, as captured by $\mu_{t}$ in (8), which is assumed to be increasing over these 500 years; cf. Table 1 . Intuitively, as can be seen in a simple non-stochastic model, a higher average growth rate in land productivity is associated with higher per-capita incomes on average on a Malthusian balanced growth path. Thus, when growth rates increase gradually over time it shows up as a gradual rise in per-capita income levels.

Recall that the paths are all generated by a Malthusian model that is stagnant by construction, in the sense that per-capita incomes cannot exhibit sustained growth. Not knowing this, one could easily interpret some decades-, or even centuries-long, growth episodes in Figure 2 as (temporary) break-outs from Malthusian stagnation.

While Figure 2 shows just a few random paths, Figure 3 shows the 5th and 95th percentiles of $\ln y_{t}$ in any given year among the 1000 simulated countries, as well as the median (the same as in Figure 2). That is, in any given year, 90 percent of the simulated countries fall within the interval defined by these two percentiles. The corresponding (normalized) paths for the five countries from Figure 1 are also shown. The paths sometimes fall outside of the interval, but mostly within.

As explained in Table 4, for all countries taken together, about $4.8 \%$ of the countryyear observations in the data fall below the 5th percentile level, and 3.7\% above the 95th percentile level, close to what we would expect. Some countries fall outside these regions more often (e.g., the Netherlands falls below the 5 th percentile in about $12.6 \%$ of the years), but even if all countries are identical except for the shocks, we should expect some of them to fall outside in some years.

Finally, consider Figure 4. The top-left panel shows how the standard deviation in $\ln y_{t}$ over time is distributed across the 1000 simulated countries. Depending on the realizations of the shocks, some have higher variation in $\ln y_{t}$ than others. The same holds for the one- and two-year serial correlations-in some runs there is higher serial correlation than in others-as shown the top-right and bottom-left panels. But as shown, there is a great deal of variation in these measures in the data too; Sweden and Italy show far less dispersion and serial correlation than England and Holland. At least some (mass of) runs have outcomes similar to those for Sweden and Italy.

Because part of the shocks to land productivity are persistent, and thus generate persistence in $\ln y_{t}$ in the simulations, higher measured serial correlation outcomes are associated with higher measured standard deviations. As seen in the bottom-right panel of Figure 4, the model is able to match the positive relationship between standard deviation and one-year serial correlation seen in the data. As mentioned above, $\sigma_{X}$ and $\sigma_{A}$ were set to match this pattern, but it is far from obvious that the model should be able to. 


\section{Conclusions}

Over the last several years researchers have compiled high-quality comprehensive per-capita income data from a couple of European countries going as far back as 1300, and up to 1800, recently summarized by Fouquet and Broadberry (2015). The data display big fluctuations in per-capita incomes over time, with a high degree of persistence, as per-capita income can move in long cycles of expansions and contractions. Can these observations really be consistent with the predictions of a standard Malthusian model, which says that per-capita incomes should be stagnant?

This paper proposes a simple exercise to come up with a tentative answer to this question. I set up a model that is Malthusian by construction, in the sense that it cannot exhibit sustained growth. Some major differences compared to a textbook Malthusian growth model is that the life-cycle structure is a more realistic, with agents living for up to 90 years, and land productivity is subject to shocks, both temporary and persistent. I then simulate the model for a set of plausible parameter values, to see how the simulated paths compare to those in the data.

It turns out that it is indeed possible for the model to match the data, as measured by standard deviation and serial correlation in per-capita incomes, given the right amount of variation in land productivity shocks. Interestingly, the simulated paths can show centuries-

long cycles of expansions and contractions in per-capita incomes. Not knowing that they are generated by a Malthusian model, one could mistakenly believe that some of the expansions constitute transitions out of Malthusian stagnation.

\section{References}

[1] Ashraf, Q., and O. Galor, 2011, Dynamics and stagnation in the Malthusian epoch, American Economic Review 101, 2003-2041.

[2] Bar, M., and O. Leukhina, 2010, Demographic transition and industrial revolution: a macroeconomic investigation, Review of Economic Dynamics 13, 424-451.

[3] Broadberry, S., B. Campbell, A. Klein, M. Overton, and B. van Leeuwen, 2011, British economic growth, 1270-1870: an output-based approach, mimeo, Nuffield College, University of Oxford. Available from:

www.nuffield.ox.ac.uk/People/sites/stephen.broadberry/SitePages/Biography.aspx

[4] Crafts, N., and T.C. Mills, 2009, From Malthus to Solow: How did the Malthusian economy really evolve?, Journal of Macroeconomics 31, 68-93. 
[5] Fernández-Villaverde, J., 2001, Was Malthus right? Economic growth and population dynamics, mimeo, University of Pennsylvania.

[6] Galor, O., 2008, The 2008 Lawrence R. Klein lecture - comparative economic development: insights from Unified Growth Theory, International Economic Review 51, 1-44.

[7] Galor, O., and D. Weil, 2000, Population, technology, and growth: from Malthusian stagnation to the demographic transition and beyond, American Economic Review 90, 806-829.

[8] Hansen, G.D., and E.C. Prescott, 2002, Malthus to Solow, American Economic Review 92, 1205-1217.

[9] Kelly, M., and C. Ó Gráda, 2010, Living standards and mortality since the middle ages, Working Paper 2010/26 University College Dublin.

[10] Lagerlöf, N.P., 2003, From Malthus to modern growth: can epidemics explain the three regimes?, International Economic Review 44, 755-777.

[11] Lagerlöf, N.P., 2006, The Galor-Weil model revisited: a quantitative exercise, Review of Economic Dynamics 9, 116-142.

[12] Lagerlöf, N.P., 2015, Malthus in Sweden, Scandinavian Journal of Economics 117, 10911133

[13] Lucas, R.E., 2002, Lectures on Economic Growth, Harvard University Press.

[14] Malanima, P, 2011, The long decline of a leading economy: GDP in Central and Northern Italy, 1300-1913, European Review of Economic History 15, 169-219.

[15] Nicolini, E.A., 2007, Was Malthus right? A VAR analysis of economic and demographic interactions in pre-industrial England, European Review of Economic History 11, 99121.

[16] Palma, N., and J. Reis, 2014, Portuguese Demography and Economic Growth, 15001850, mimeo, University of Warwick. Available from:

www2.warwick.ac.uk/fac/soc/economics/research/centres/cage/events/conferences/greatdivergence14/

[17] Reis, J., C.A. Martins, and L.F. Costa, 2013, From major power to economic backwater: Portugal's GDP 1500-1850, mimeo, University of Warwick, Available from:

ww w 2.warwick.ac.uk/fac/soc/economics/research/centres/cage/events/conferences/greatdivergence14/ 
[18] Schön, L., and O. Krantz. 2012, The Swedish economy in the early modern period: constructing historical national accounts 1560-2000, European Review of Economic History 16, 529-49.

[19] Sharp, P., H. Strulik, and J. Weisdorf, The determinants of income in a Malthusian equilibrium, Journal of Development Economics 97, 112-117.

[20] Statistics Sweden, 1969, Historical Statistics of Sweden, Part 1: Population 1720-1967, AB Allmänna Förlaget, Stockholm. Available from:

www.scb.se/Grupp/Hitta_statistik/Historisk_statistik/__Dokument/Historisk-statistik-for-Sverige-Del-1.pdf

[21] van Zanden, J.L., and B. van Leeuwen, 2012, Persistent but not consistent: the growth of national income in Holland 1347-1807, Explorations in Economic History 49, 119-30.

[22] Wu, L., R, Dutta, D.K. Levine, and N.W. Papageorge, 2014, Entertaining Malthus: bread, circuses and economic growth, mimeo, European University Institute. Available from:

www.dklevine.com/papers/circuses.pdf 


\begin{tabular}{|c|c|c|}
\hline Parameter & Value & Interpretation/comment \\
\hline$T$ & 90 & Maximum age \\
\hline$\underline{B}$ & 18 & $\begin{array}{l}\text { Age when agents first become economically and reproduc- } \\
\text { tively active }\end{array}$ \\
\hline $\bar{B}$ & 40 & Last age of being economically and reproductively active \\
\hline$\alpha$ & .4 & Land share of output; same as Hansen and Prescott (2002) \\
\hline$\gamma$ & .1 & 10 percent of labor income allocated to conceiving children \\
\hline$\sigma_{A}$ & .075 & Standard deviation in permanent shock \\
\hline$\sigma_{X}$ & .1125 & $\begin{array}{l}\text { Standard deviation in temporary shock; about } 1.5 \text { times the } \\
\text { standard deviation for the permanent shock. Both are set to } \\
\text { match the standard deviations and serial correlations in the } \\
\text { data. }\end{array}$ \\
\hline$\mu_{t}$ & $.01(t / 500)^{2}$ & $\begin{array}{l}\text { Mean growth rate equals } 1 \text { percent per year in } 1800 \text { (after } 500 \\
\text { years); rise in growth rates closer to the end. Set to match } \\
\text { data on population levels. }\end{array}$ \\
\hline$\rho$ & .5 & $\begin{array}{l}\text { Substitutability between age cohorts when determining ef- } \\
\text { fective labor set half-way between Cobb-Douglas and perfect } \\
\text { substitutability. }\end{array}$ \\
\hline
\end{tabular}

Table 1: Values for some of the parameters. 


\begin{tabular}{l|l} 
Ages $(j-1)$ & Death rate $\left(d_{j}\right)$ \\
\hline \hline 0 & .204 \\
$1-2$ & .053 \\
$3-4$ & .028 \\
$5-9$ & .013 \\
$10-14$ & .007 \\
$15-19$ & .007 \\
$20-24$ & .008 \\
$25-29$ & .010 \\
$30-34$ & .012 \\
$35-39$ & .012 \\
$40-44$ & .016 \\
$45-49$ & .018 \\
$50-54$ & .022 \\
$55-59$ & .027 \\
$60-64$ & .041 \\
$65-69$ & .059 \\
$70-74$ & .225 \\
$75-79$ & \\
$80-89$ & .092 \\
90 & .020 \\
\hline \hline
\end{tabular}

Table 2: Age-specific death probabilities. 


\begin{tabular}{l|l}
$j$ & $\beta_{j}$ \\
\hline \hline 18 & .0010 \\
32 & .1350 \\
40 & .0053 \\
\hline \hline
\end{tabular}

Table 3: Weights on the labor inputs of three cohorts.

\begin{tabular}{l|l|l} 
Country & $\begin{array}{l}\text { Fraction years below 5th per- } \\
\text { centile }\end{array}$ & $\begin{array}{l}\text { Fraction years above 95th } \\
\text { percentile }\end{array}$ \\
\hline \hline UK & .044 & .086 \\
Netherlands & .126 & .042 \\
Italy & .000 & .022 \\
Sweden & .012 & .000 \\
Portugal & .041 & .000 \\
\hline All & .048 & .037 \\
\hline \hline
\end{tabular}

Table 4: Fraction years in which log GDP per capita for each of the countries fell below the 5th percentile and above the 95th percentile of the Monte Carlo simulation, and the corresponding number for all countries taken together. 


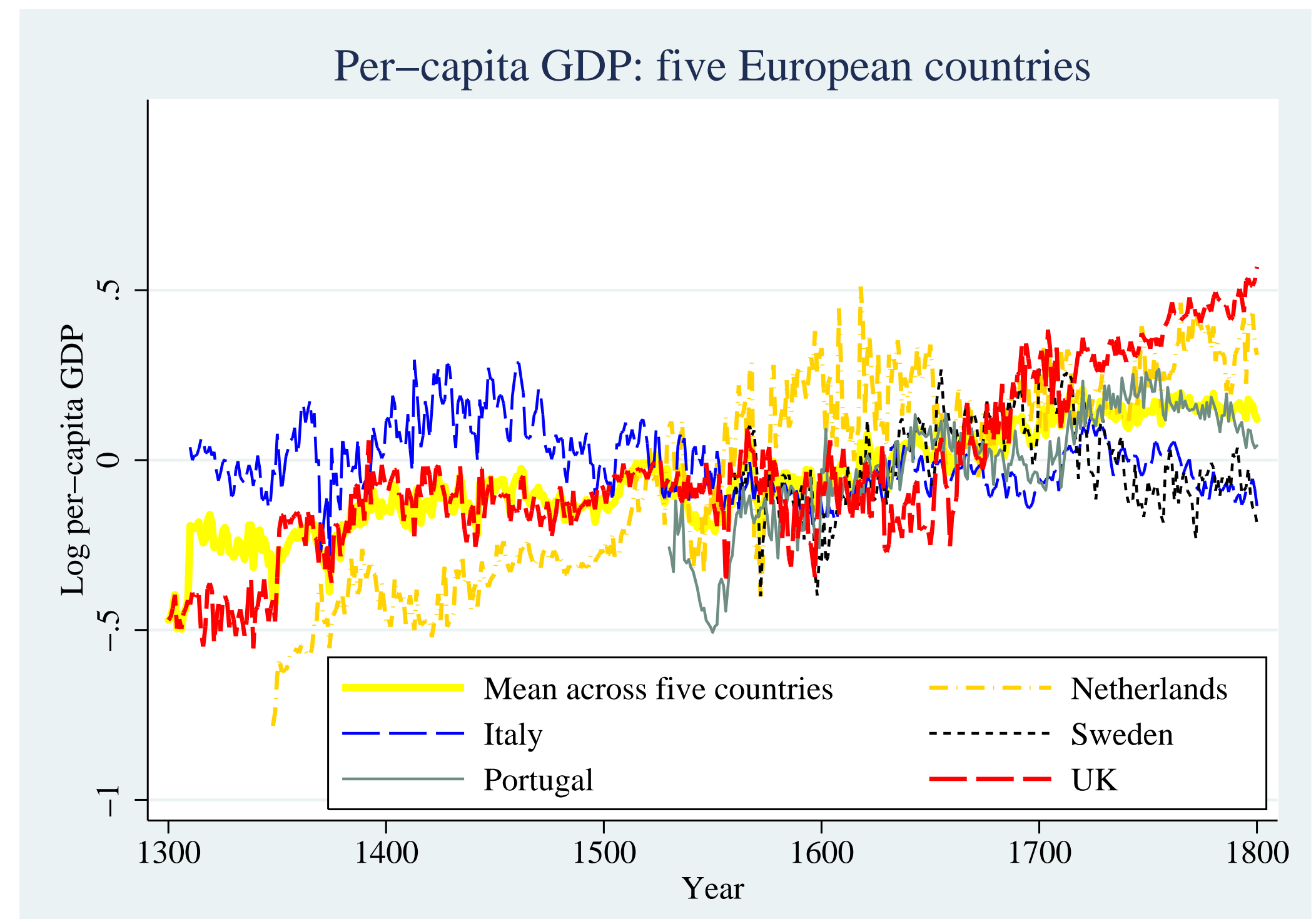

Figure 1: Data over log GDP per capita. The series are normalized for each country to equal one (zero in logs) on average across all years with available data. 


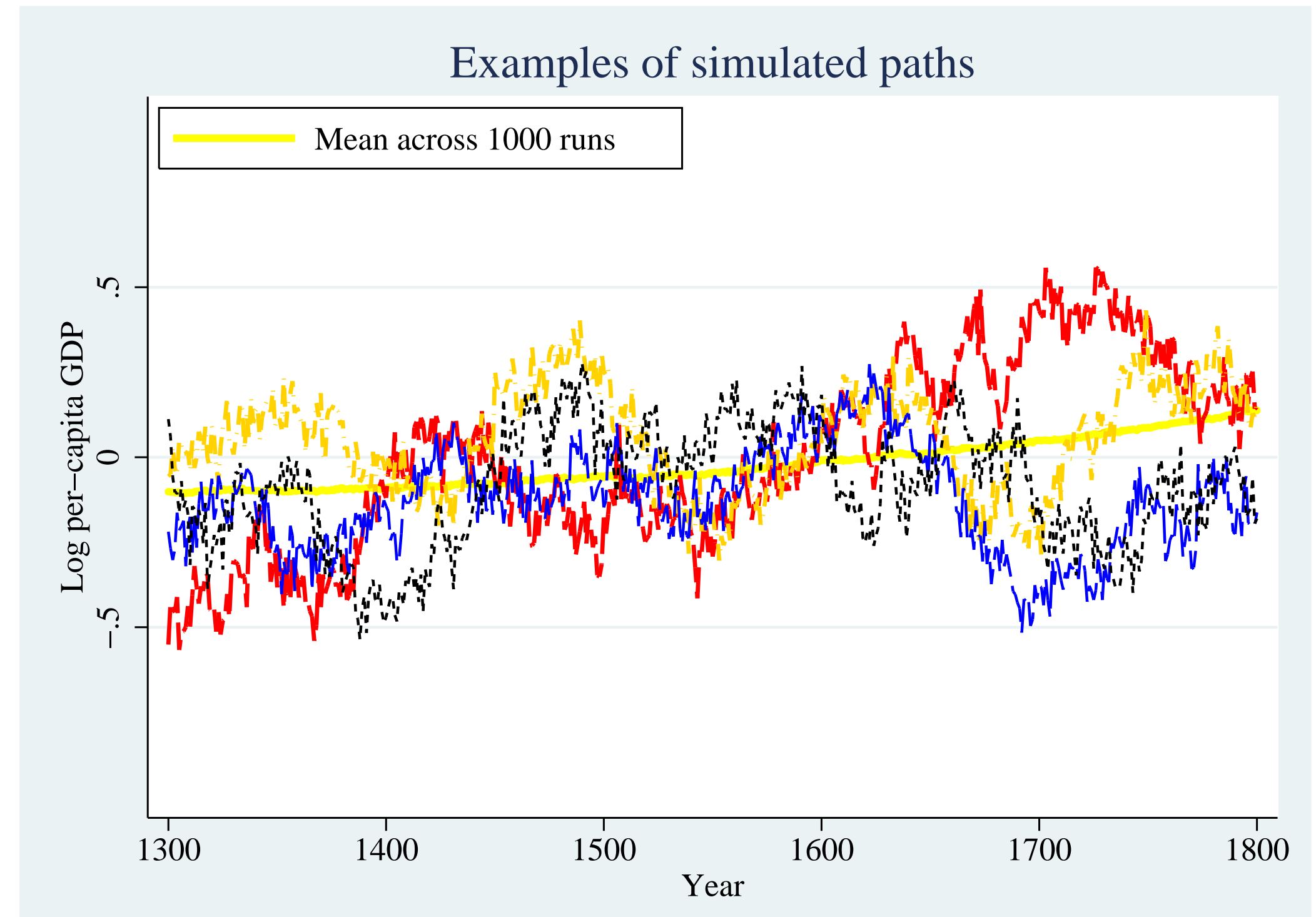

Figure 2: Examples of paths of log GDP per capita for four different simulated economies, normalized to average one (zero in logs), and the mean for each year in the whole Monte Carlo simulation (1000 runs including the ones shown). 


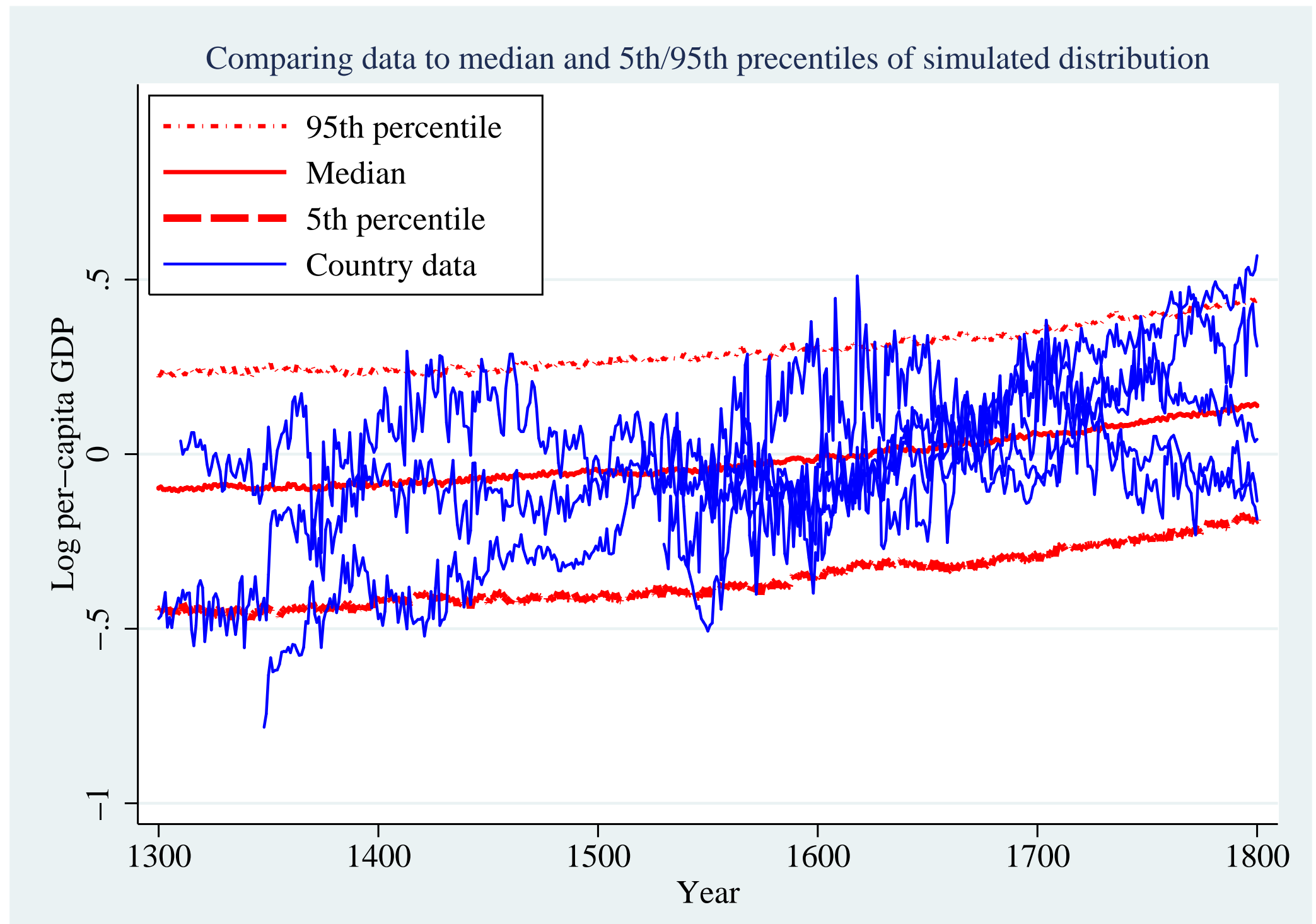

Figure 3: This figure compares the time paths in log GDP per capita for the five countries in Figure 1 to the median log GDP per capita in the Monte Carlo simulation, as well as the associated 5th and 95th percentile runs for each year. 


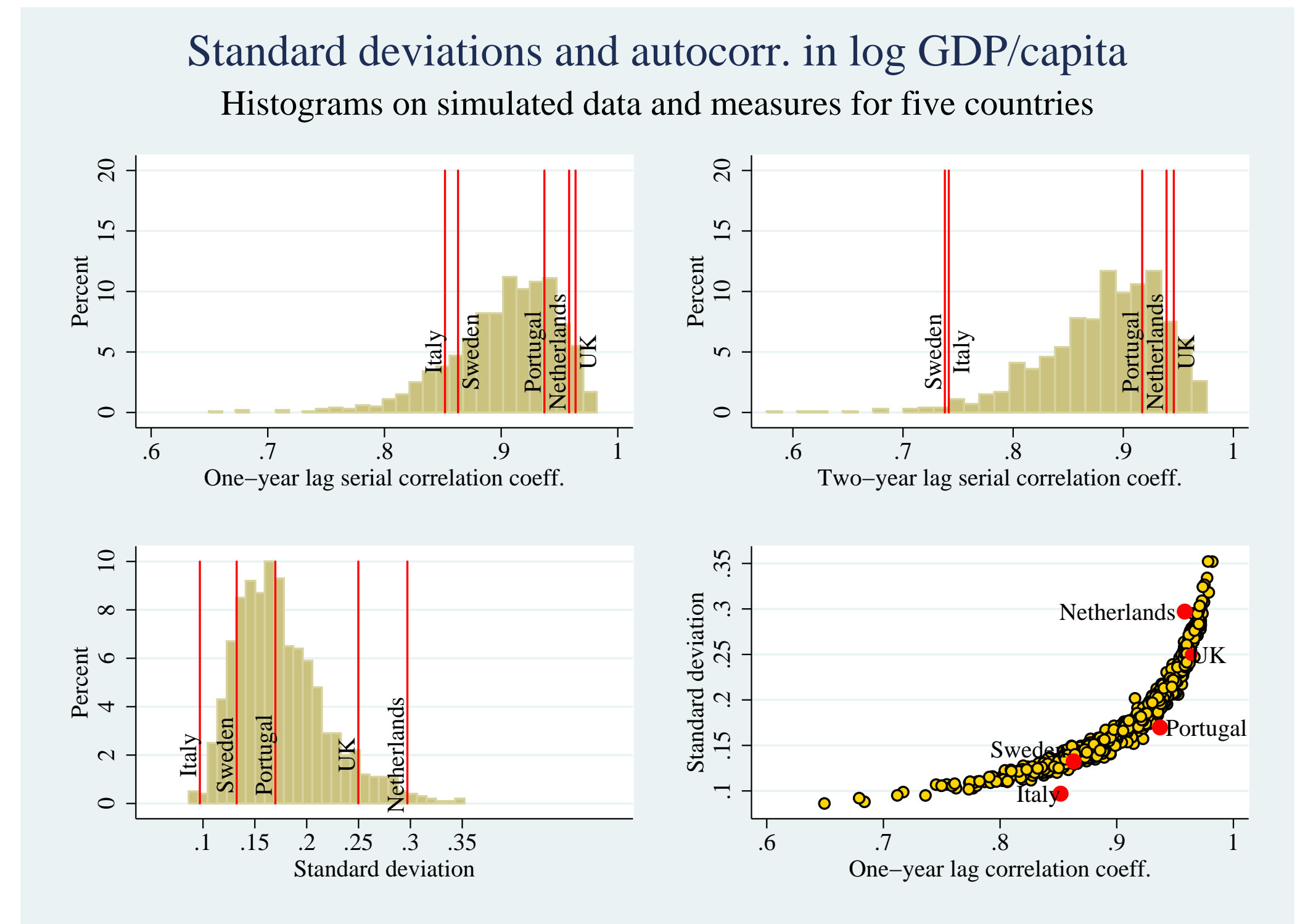

Figure 4: For each economy in the Monte Carlo simulation, the standard deviation and serial correlation coefficients (one and two year lags) were calculated. This figure shows how these moments were distributed across the 1000 simulated economies, as well as the corresponding values for the five European economies. 